\title{
WILLINGNESS-TO-PAY FOR INSULIN IN DIABETES TREATMENT: A SYSTEMATIC REVIEW AND META-ANALYSIS
}

\author{
Le Thi Kieu Oanh*, Tran Thi Ngoc Van*, Hoang Thy Nhac Vu*
}

\section{ABSTRACT}

Background: Insulin treatment is necessary for all patients with type 1 diabetes and a subset of patients with type 2 diabetes. However, lifetime insulin treatment is relatively costly that has put a heavy financial burden on insulindependent diabetics. Several studies thus have been conducted widely to estimate diabetes patients' willingness to pay (WTP) for insulin therapies worldwide. This study aimed to derive the diabetes patients' WTP for insulin therapy from the results of previous research studies. Methods: A systematic review and meta-analysis of diabetes patients' WTP for insulin was conducted. All studies were searched and derived from PubMed combined with MeSH, Cochrane library combined with $\mathrm{MeSH}$, ScienceDirect, and Springer Nature. The WTP values were estimated for three different types of insulin, including short-acting, rapid-acting insulin; long-acting, slow-acting insulin, and mixed insulin. Review Manager 5.1.4 software was used to conduct the meta-analysis. Results: Twelve studies were identified by the systematic review, in which eight studies were eligible for a meta-analysis. Most studies were conducted in high-income countries (83.3\%), mainly in America (41.7\%) and Europe $(33.3 \%)$. The insulin formulation with the highest mean WTP value was Humalog Mix25 insulin, which was recorded at 410.42 USD per month in the UK and more than 120 USD per month in France, Italy, Spain, and Germany; while most of the other insulin formulations had mean WTP values less than 120

\footnotetext{
*University of Medicine and Pharmacy, Ho Chi Minh City

Responsible person: Hoang Thy Nhac Vu

Email: hoangthynhacvu@ump.edu.vn

Date of receipt: 15/7/2021

Date of scientific judgment: 05/8/2021

Reviewed date: $20 / 8 / 2021$
}

USD per month. Compared to diabetes patients, general populations were willing to pay less for insulin, which was observed in the case of Humalog Mix25 insulin (mean 95.77 USD per month vs 205.89 USD per month) and inhaled insulin (mean 50.43 USD per month compared to more than 120 USD per month). The metaanalysis showed the WTP value for insulin was 74.15 USD per month (95\% CI; 55.82 - 92.48).

Conclusion: This study showed a comparison of WTP values for different insulin formulations worldwide. The mean WTP value for insulin derived from all previous research may provide an initial understanding of the individuals' preference and WTP. This information could contribute to the effort of managing diabetes and reducing the financial burden of this chronic disease.

Keywords: Willingness to pay, insulin, diabetes, systematic review, meta-analysis.

\section{INTRODUCTION}

The burden of diabetes management has become a pressing concern to the healthcare system of several countries. With a mortality rate ranking at third, diabetes has become one of the top ten causes of death worldwide [1-2]. The statistics of the International Diabetes Federation reported that there were 463 million adults aged from 20-79 years old living with diabetes in 2019 and predicted that the number of adult diabetics would reach 578 million in 2030 and 700 million in 2045 worldwide. Global diabetes health expenditures were anticipated to cost $\$ 760$ billion per year, reaching $\$ 825$ billion by 2030 and $\$ 845$ billion by 2045 due to the growing number of people with diabetes and the escalating prices of medical goods and services [3]. 
As a chronic disease, diabetes requires lifetime medications and the treatment goal is to avoid major morbidity and mortality and to reduce the risk of related complications by optimal glycemic control [4]. Diabetes medications are classified into insulins and non-insulins. Insulin-dependent diabetics, who are either with type 1 diabetes or with type 2 diabetes and failures to non-insulin therapies, benefit from insulin therapies. Compared to non-insulins, insulins are relatively costly since the doses must be tailored to each patient and the administration requires special devices. Additionally, among insulins, newer formulations such as rapid-acting insulin analogs have been provided at a significantly higher price. The financial burden of insulin thus has become more intolerable for insulindependent diabetics in particular and the healthcare system as a whole.

Several studies were conducted to estimate the willingness to pay (WTP) for insulin therapies to understand patients' preferences. This information could support the effort of reducing the financial burden for insulin-dependent diabetics. Doctors could find an optimal treatment approach for each individual patient, while policymakers could efficiently offer price negotiations and allocate resources for insulins marketed in their countries.

This systematic review and meta-analysis study was carried out to derive the patients' WTP for insulin from previous studies worldwide.

\section{METHOD}

Search strategy: This study was designed in accordance with the Preferred Reporting Items for Systematic Reviews and MetaAnalyses (PRISMA) guidelines (Figure1) [1]. Four electronic databases, including
PubMed combined with MeSH, Cochrane library combined with MeSH, ScienceDirect, and SpringerNature were used to find all original research studies that reported the diabetes patients' WTP for insulin which were written in English, free full-text, and published till August of 2021.

The PICO approach was used to choose search terms from the list of medical subject headings $(\mathrm{MeSH})$. The final search formula was ((Willingness to pay" OR "Willingnessto-pay" OR "WTP" OR "Discrete choice analysis" OR "Contingent Valuation Method" OR "Patient Preference" OR "Choice Behavior" OR "Surveys and Questionnaires" OR "Financing, Personal") AND ("Diabetes" OR "Diabetic" OR "Diabetes Mellitus" OR "Diabetes Mellitus, Type 1" OR "Diabetes Mellitus, Type 2" OR "Insulin")). The search range was in the titles and summaries of published studies.

The study selection process followed the PRISMA diagram and the quality of selected studies was evaluated by the PREFS checklist [1, 2]. There were 7644 studies identified from applying the search formula in all four databases. Duplicate removing and screening process narrowed down to 79 fulltext studies. Twelve studies were eligible for the systematic review, in which eight studies were eligible for the meta-analysis.

Statistical methods: In this review, all the studied WTP values were uniformly presented as a mean value with a $95 \%$ confidence interval (CI). For WTP values which had been reported as a mean $( \pm \mathrm{SD})$ or a mean $( \pm \mathrm{SE})$, the following formulas were used to convert SD and SE to $95 \%$ CI: $S D=$ $S E * \sqrt{N} ; \quad 95 \% C I=\bar{X} \pm Z * \frac{S D}{\sqrt{N}} ;(S D:$ standard deviation; SE: standard error; 95\% CI: 95\% confidence intervals; $\bar{X}$ : mean of WTP value; $Z=1,96 ; N$ : sample size). For WTP values which had been reported only 
for subgroups, an average approach was used to obtain the WTP value for the total sample. All the mean WTP values with $95 \%$ CI then were converted to USD and VND values in 2021 using exchange rates and the medical consumer price index (CPI) to make comparisons [3].

Microsoft Excel was used to develop the search strategy and search formula. Review Manager 5.1.4 software was used to perform the meta-analysis with a random effect model, following the recommendation from the Cochrane Collaboration [4]. The metaanalysis results were presented by a forest plot diagram and tested for heterogeneity by the $\mathrm{I}^{2}$ test, in which the heterogeneity was relatively high if $\mathrm{I}^{2}>50 \%$.

\section{RESULTS}

Characteristics of selected studies: Twelve studies on estimating WTPs for insulin were included in the systematic review, in which seven studies were published before 2010 and five studies were published since 2011. Ten studies were conducted in high-income countries which were classified according to the New World Bank country categories by income level [5]. Type 2 diabetes patients were the most popular subject of interest. (Table 1)

Willingness to pay for insulin: Of twelve selected studies, $41.7 \%$ estimated the WTP for long-acting and slow-acting insulin, $33.3 \%$ for rapid-acting and short-acting insulin, and $25.0 \%$ for mixed insulin (Table 2). Eight studies (fifteen data) were metaanalyzed on WTP for insulin. The results showed that the overall mean WTP for insulin was 74.15 USD per month (95\% CI; 55.82 - 92.48). The results of the heterogeneous assessment showed a relatively high heterogeneity $\left(\mathrm{I}^{2}=99 \%, \mathrm{df}=14\right.$, and $\mathrm{p}<0.05$ ). (Figure 2)

Table 1. Characteristics of twelve WTP studies for insulin worldwide published till August 2021

\begin{tabular}{|c|c|c|c|}
\hline \multirow[b]{2}{*}{ Characteristics of studies } & \multicolumn{3}{|c|}{ Insulin } \\
\hline & $\begin{array}{l}\text { Short-acting, rapid- } \\
\text { acting insulin } \\
\text { ( } n=4 \text { studies) }\end{array}$ & $\begin{array}{l}\text { Long-acting, slow- } \\
\text { acting insulin } \\
\text { ( } n=5 \text { studies) }\end{array}$ & $\begin{array}{l}\text { Mixed insulin } \\
\text { ( } n=3 \text { studies) }\end{array}$ \\
\hline \multicolumn{4}{|l|}{ Year of publication } \\
\hline $1998-2010$ & {$[6-9]$} & {$[10]$} & {$[11,12]$} \\
\hline $2011-2021$ & & [13-16] & [17] \\
\hline \multicolumn{4}{|l|}{ Sample size } \\
\hline$\leq 100$ & {$[6,8]$} & & [11] \\
\hline $101-500$ & {$[7,9]$} & {$[10,13,15]$} & [12] \\
\hline $501-1000$ & & & {$[17]$} \\
\hline$>1000$ & & {$[14,16]$} & \\
\hline \multicolumn{4}{|l|}{ Countries } \\
\hline The United State & [9] & & \\
\hline Sweden & & {$[14,15]$} & \\
\hline Canada & {$[7,8]$} & {$[10]$} & [11] \\
\hline Australia & [6] & & \\
\hline United Kingdom & & [13] & \\
\hline India & & & [17] \\
\hline Multinational & & [16] & {$[12]$} \\
\hline
\end{tabular}




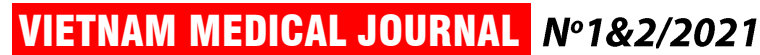

\begin{tabular}{|c|c|c|c|}
\hline \multicolumn{4}{|l|}{ Continents } \\
\hline Europe & & [13-15] & [12] \\
\hline America & [7-9] & {$[10]$} & [11] \\
\hline Asia & & & [17] \\
\hline Australia & [6] & & \\
\hline Multi-continent & & [16] & \\
\hline \multicolumn{4}{|l|}{ Countries by income level } \\
\hline High income & [6-9] & {$[10,13-15]$} & {$[11,12]$} \\
\hline Low and middle income & & {$[16]$} & {$[17]$} \\
\hline \multicolumn{4}{|l|}{ Participants in the survey } \\
\hline Diabetes patients & {$[6,8,9]$} & {$[9,13]$} & \\
\hline Type-2 diabetes patients & & {$[14,16]$} & {$[12,17]$} \\
\hline General population & [7] & [15] & [11] \\
\hline
\end{tabular}

Table 2. Willingness to pay (WTP) values of insulin (USD 2021 and VND 2021)

\begin{tabular}{|c|c|c|c|}
\hline Types of insulin & Population (year of study) & $\begin{array}{l}\text { Mean WTP (95\% } \\
\text { CI) per month } \\
\text { (USD) }\end{array}$ & $\begin{array}{l}\text { Mean WTP (95\% CI) } \\
\text { per month (VND) }\end{array}$ \\
\hline \multicolumn{4}{|c|}{ Short-acting, rapid-acting insulin } \\
\hline Insulin lispro & 83 patients in Australia (1998) [6] & $\begin{array}{c}41.80 \\
(40.10-43.50)\end{array}$ & $\begin{array}{c}967,043 \\
(927,724-1,006,362)\end{array}$ \\
\hline \multirow{3}{*}{ Inhaled insulin } & 96 patients in Canada (2005) [7] & $\begin{array}{c}205.89 \\
(179.12-232.66) \\
\end{array}$ & $\begin{array}{c}4,763,215 \\
(4,143,902-5,382,528) \\
\end{array}$ \\
\hline & \begin{tabular}{|l|}
120 individuals of general \\
population in Canada (2007) [8]
\end{tabular} & $\begin{array}{c}95.77 \\
(84.63-106.91)\end{array}$ & $\begin{array}{c}2,215,639 \\
(1,957,843-2,473,435)\end{array}$ \\
\hline & 1103 patients in US (2009) [9] & $77.40(*)$ & $1,790,624(*)$ \\
\hline \multicolumn{4}{|c|}{ Long-acting, slow-acting insulin } \\
\hline \multirow{2}{*}{$\begin{array}{l}\text { Oral long-acting, } \\
\text { slow-acting insulin }\end{array}$} & $\begin{array}{l}227 \text { patients in Canada (2008) } \\
{[10]}\end{array}$ & $\begin{array}{c}27.83 \\
(0.11-55.55)\end{array}$ & $\begin{array}{c}643,951 \\
(2,514-1,285,149)\end{array}$ \\
\hline & 252 patients in UK (2011) [13] & $31.07(*)$ & $718,806(*)$ \\
\hline Insulin detemir & $\begin{array}{l}333 \text { patients in Sweden (2012) } \\
{[14]}\end{array}$ & $1.88(*)$ & $43,526(*)$ \\
\hline \multirow{5}{*}{ Basal insulin } & $\begin{array}{l}646 \text { patients in North American } \\
\text { countries (2017) [16] }\end{array}$ & $\begin{array}{c}77.38 \\
(47.84-106.92)\end{array}$ & $\begin{array}{c}1,790,109 \\
(1,106,720-2,473,594)\end{array}$ \\
\hline & $\begin{array}{l}1537 \text { patients in South American } \\
\text { countries (2017) [16] }\end{array}$ & $\begin{array}{c}51.58 \\
(31.99-71.17)\end{array}$ & $\begin{array}{c}1,193,406 \\
(809,545-1,646,518)\end{array}$ \\
\hline & $\begin{array}{l}1575 \text { patients in European } \\
\text { countries (2017) [16] }\end{array}$ & $\begin{array}{c}64.81 \\
(44.36-86.26)\end{array}$ & $\begin{array}{c}1,499,408 \\
(1,026,380-1,995,625)\end{array}$ \\
\hline & $\begin{array}{l}333 \text { patients in Sweden (2012) } \\
{[14]}\end{array}$ & $43.23(*)$ & $1,000,220(*)$ \\
\hline & $\begin{array}{l}987 \text { individuals of general } \\
\text { population and 1034 patients in } \\
\text { Sweden (2016) [15] }\end{array}$ & $41.60(*)$ & $962,511(*)$ \\
\hline \multicolumn{4}{|l|}{ Mixed insulin } \\
\hline \multirow{2}{*}{$\begin{array}{l}\text { Humalog Mix25 } \\
\text { insulin }\end{array}$} & 53 patients in France (2004) [12] & $\begin{array}{c}310.06 \\
(107.76-512.36)\end{array}$ & $\begin{array}{c}7,173,150 \\
(2,492,991- \\
11,853,449) \\
\end{array}$ \\
\hline & $\begin{array}{l}60 \text { patients in Germany (2004) } \\
{[12]}\end{array}$ & $\begin{array}{c}267.44 \\
(122.24-412.64)\end{array}$ & $\begin{array}{c}6,187,288 \\
(2,828,125-9,546,426) \\
\end{array}$ \\
\hline
\end{tabular}


No 1\&2/2021 VIETNAM MEDICAL JOURNAL

\begin{tabular}{|c|l|c|c|}
\hline & 56 patients in Italy (2004) [12] & $\begin{array}{c}120.32 \\
(38.79-201.85)\end{array}$ & $\begin{array}{c}2,783,669 \\
(897,437-4,669,800)\end{array}$ \\
\cline { 2 - 4 } & 60 patients in Spain (2004) [12] & $\begin{array}{c}316.88 \\
(187.26-446.50)\end{array}$ & $\begin{array}{c}7,330,948 \\
(4,332,324-17,447,031)\end{array}$ \\
\cline { 2 - 4 } & 61 patients in UK (2004) [12] & $\begin{array}{c}410.42 \\
(177.00-648.84)\end{array}$ & $\begin{array}{c}(4,095,155 \\
132,4896-581)\end{array}$ \\
\cline { 2 - 4 } & 80 individuals of general & 50.43 & $\begin{array}{c}1,166,768 \\
(924,055-1,409,793)\end{array}$ \\
\hline $\begin{array}{c}\text { Humulin 30/70 } \\
\text { insulin }\end{array}$ & population in Canada (2000) [11] & $(39.94-60.94)$ & 65,934 \\
& population in Canada (2000) [11] & $2.85(2.57-3.13)$ & $(59,394-72,474)$ \\
\hline $\begin{array}{c}\text { Biphasic Insulin } \\
\text { Aspart 30/70 }\end{array}$ & 505 patients in India (2021) [17] & $\begin{array}{c}15.69 \\
(10.71-20.67)\end{array}$ & $\begin{array}{c}362,930 \\
(247,710-478,151)\end{array}$ \\
\hline
\end{tabular}

(*) $95 \%$ CI was not available

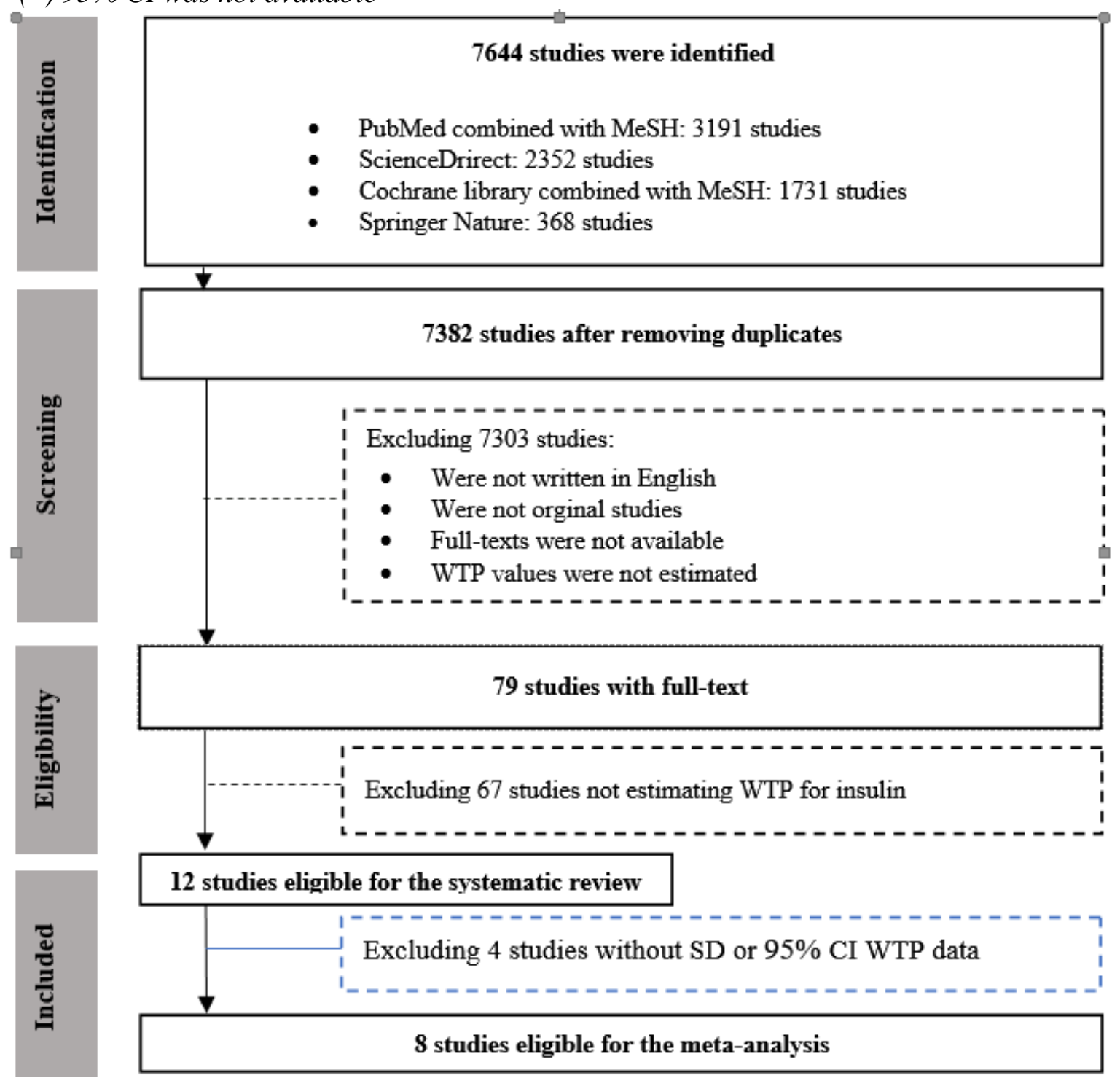

Figure 1. The systematic review study selection process following the PRISMA diagram 


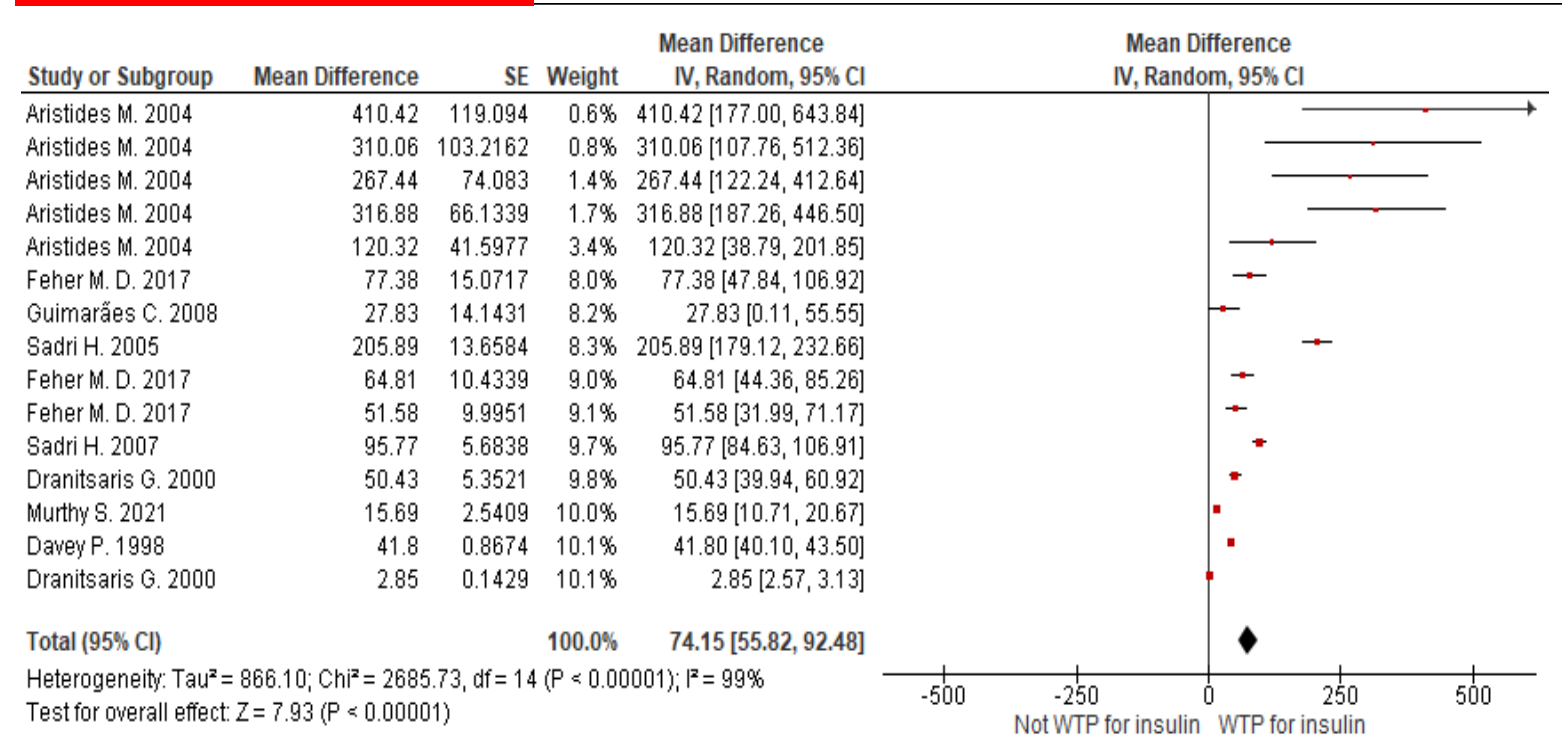

Figure 2. Random effect model of the overall mean WTP for insulin with $95 \%$ confidence interval

\section{DISCUSSION}

This review included a total of twelve studies on estimating WTP for insulin. The majority of studies were published before 2010 (58\%), with a focus on estimating the WTP for the short-acting and rapid-acting insulin (57\%), which showed a major concern on the cost of this very first insulin formulation during that period of time [18]. The interest in estimating WTP for insulins then was completely shifted into the newer insulin formulations, in which estimating WTP for the long-acting, slow-acting insulin accounted for $80 \%$ of the total studies published since 2011 . While only two studies were published in low and middle income countries, there were 10 studies published in high income countries, which may imply differences in the research interest and resources.

This systematic review showed that the insulin formulation with the highest mean WTP value was Humalog Mix25 insulin, which was estimated at 410.42 USD per month in the UK and more than 120 USD per month in France, Italy, Spain, and Germany [12]. This could be explained partially by the significantly higher effectiveness of Humalog Mix25 insulin which was better postprandial glycemic control and lower incidence of nocturnal hypoglycemia [19]. In contrast, estimated mean WTPs of insulin formulations including insulin lispro, oral long-acting, slow-acting insulin, Insulin detemir, basal insulins, Humulin 30/70 insulin, and Biphasic Insulin Aspart 30/70 were all less than 120 USD per month [6, 1011, 13-17]. In Canada, compared to diabetes patients, general populations were willing to pay less than half for inhaled insulin (mean 95.77 USD per month vs 205.89 USD per month) [7, 8]. A similar result was observed that general population was willing to pay less than patients (mean 50.43 USD per month compared to more than 120 USD per month) when comparing the mean WTPs of Humalog Mix25 insulin among countries $[11,12]$. The lowest mean WTP values were 1.88 USD per month for Insulin detemir in 
No1\&2/2021 VIETNAM MEDICAL JOURNAL

the case of 333 Sweden's patients in 2012 and 2.85 USD per month for Humulin 30/70 insulin in the case of 80 individuals of Canada's general population in 2000 [11,14].

The meta-analysis showed that participants were willing to pay for insulin rather than non-insulin and the mean WTP value derived was 74.15 USD per month. However, studies showed a relatively high heterogeneity with $\mathrm{I}^{2}>99 \%$ and $\mathrm{p}<0.05$. This suggested further research to carry out subgroup analyses with more consistency to gain a more precise overall effect from the random effects model.

\section{CONCLUSION}

This study provided an overview of WTP values for different insulin formulations worldwide. The mean WTP value for insulin derived from all previous research may provide an initial understanding of the individuals' preference and WTP. This information could contribute to the effort of managing diabetes and reducing the financial burden of this chronic disease.

\section{REFERENCES}

1. Liberati A., Altman D. G., Tetzlaff J. et al. (2009), "The PRISMA statement for reporting systematic reviews and metaanalyses of studies that evaluate health care interventions: explanation and elaboration", PLoS Med. 6 (7), e1000100.

2. Joy S. M., Little E., Maruthur N. M. et al. (2013), "Patient preferences for the treatment of type 2 diabetes: a scoping review", PharmacoEconomics. 31 (10), 877-892.

3. U.S.Bureau of Labor statistics (2021), Consumer Price Index, available at https://www.bls.gov/cpi/factsheets/medicalcare.htm, Access on 12/08/2021.

4. Higgins J G. S. (2011), Cochrane handbook for systematic reviews of interventions version 5.1.0. 2011, available at http://handbook.cochrane.org/, Access on 12/08/2021.

5. The World Bank (2021), World Bank Country and Lending Groups, available at https://datahelpdesk.worldbank.org/knowledg ebase/articles/906519, Access on 12/08/2021.

6. Davey P., Grainger D., MacMillan J. et al. (1998), "Economic evaluation of Insulin Lispro versus Neutral (Regular) Insulin therapy using a willingness-to-pay approach", Pharmacoeconomics. 13 (3), 347-358.

7. Sadri H., MacKeigan L. D., Leiter L. A. et al. (2005), "Willingness to pay for inhaled insulin: a contingent valuation approach", Pharmacoeconomics. 23 (12), 1215-1227.

8. Sadri H. (2007), "Contingent valuation of inhaled insulin: a Canadian perspective", Journal of medical economics. 10 (4), 475487.

9. Pinto S. L., Holiday-Goodman M., Black C. D. et al. (2009), "Identifying factors that affect patients' willingness to pay for inhaled insulin", Res Social Adm Pharm. 5 (3), 253261.

10. Guimarães C., Marra C. A., Colley L. et al. (2009), "Socioeconomic differences in preferences and willingness-to-pay for insulin delivery systems in type 1 and type 2 diabetes", Diabetes Technol Ther. 11 (9), 567-573.

11. Dranitsaris G., Longo C. J. , Grossman L. D. (2000), "The economic value of a new insulin preparation, Humalog Mix 25. Measured by a willingness-to-pay approach", Pharmacoeconomics. 18 (3), 275-287.

12. Aristides M., Weston A. R., FitzGerald P. et al. (2004), "Patient Preference and Willingness-to-Pay for Humalog Mix25 Relative to Humulin 30/70: A Multicountry Application of a Discrete Choice Experiment", Value in Health. 7 (4), 442-454.

13. Lloyd A., Nafees B., Barnett A. H. et al. (2011), "Willingness to pay for improvements in chronic long-acting insulin therapy in individuals with type 1 or type 2 diabetes mellitus", Clin Ther. 33 (9), 12581267. 
14. Jendle J., Ridderstråle M., Torfvitt O. et al. (2012), "Willingness-to-pay for benefits associated with basal insulin treatment of type 2 diabetes", J Med Econ. 15 (2), 261263.

15. Olofsson S., Norrlid H. , Persson U. (2016), "Preferences for improvements in attributes associated with basal insulin: a time trade-off and willingness-to-pay survey of a diabetic and non-diabetic population in Sweden", $J$ Med Econ. 19 (10), 945-958.

16. Feher M. D., Brazier J., Schaper N. et al. (2016), "Patients' with type 2 diabetes willingness to pay for insulin therapy and clinical outcomes", BMJ Open Diabetes Research \&amp; Care. 4 (1), e000192.

17. Murthy S., Aneja P., Asirvatham A. J. et al. (2021), "Understanding Patients'
Willingness to Pay for Biphasic Insulin Aspart 30/70 in a Pen Device for Type 2 Diabetes Treatment in an Out-of-Pocket Payment Market", Pharmacoecon Open. 5(2), 261-273.

18. McEwen L. N., Casagrande S. S., Kuo S. et al. (2017), "Why Are Diabetes Medications So Expensive and What Can Be Done to Control Their Cost?", Curr Diab Rep. 17 (9), 71.

19. Malone J. K., Woodworth J. R., Arora V. et al. (2000), "Improved postprandial glycemic control with Humalog Mix75/25 after a standard test meal in patients with type 2 diabetes mellitus", Clin Ther. 22 (2), 222230. 